\title{
PENGARUH VARIASI HOLDING TIME DAN MEDIA QUENCHING TERHADAP NILAI KEKERASAN BAJA DENGAN KADAR KARBON 0,192wt.\%
}

\author{
Siska Titik Dwiyati(1,*), Muhammad Bagus Priyo Hutomo ${ }^{(1)}$ dan Ferry Budhi \\ Susetyo $^{(2)}$ \\ ${ }^{(1)}$ Program Studi Pendidikan Vokasional Teknik Mesin \\ ${ }^{(2)}$ Program Studi Teknik Mesin \\ Universitas Negeri Jakarta \\ ${ }^{(*)}$ Email : $\underline{\text { siska.td@gmail.com }}$
}

\begin{abstract}
ABSTRAK
Pada penelitian ini akan dilakukan upaya peningkatan kekerasan dari material baja karbon. Berdasarkan hasil uji OES didapatkan hasil komposisi karbon dalam baja tersebut sebesar 0,192 wt\%. Untuk itu akan dilakukan pemanasan dalam tungku dengan suhu yang ditetapkan yaitu $1000^{\circ} \mathrm{C}$. Kemudian dilakukan beberapa variasi waktu penahanan (holding time) di dalam tungku yaitu 30, 60 dan 90 menit. Setelah ditahan kemudian material tersebut di variasikan kembali untuk dua media pendingin yaitu oli dan coolant. Setelah dilakukan quenching kemudian diukur nilai kekerasannya dengan alat uji vickers. Setelah pengujian kekerasan semua selesai kemudian dilanjutkan dengan pengamatan foto mikro dengan mikroskop optik. Dari hasil pengujian maupun pengamatan dapat diketahui semakin lama waktu holding time maka kekerasan semakin naik. Terakhir, pada pengamatan struktur mikro pada spesimen terbentuk fasa ferit dan perlit.
\end{abstract}

Kata kunci: baja karbon rendah, holding time, quenching, kekerasan, foto mikro

\section{Pendahuluan}

Baja karbon rendah seperti diketahui sangat banyak digunakan dalam kehidupan sehari-hari (Alwarits dkk, 2014). Klasifikasi baja dibagi menjadi tiga yaitu baja karbon rendah, baja karbon menengah dan baja karbon tinggi (Subagyo, 2017). Dengan semakin berkembangnya industri logam, mendorong untuk lebih ditingkatkan lagi pengerasan dari baja (Murtiono, 2012). Baja karbon rendah relatif sulit dikeraskan untuk mencapai kekerasan yang diinginkan. Biasanya pengerasan baja karbon rendah dengan melakukan pengerasan pada permukaannya saja (Setiamarga dkk, 2017). Namun ada penelitian mengeraskan baja dengan media soalar (Purwanto, 2011). Dalam proses pengerasan baja banyak faktor yang berpengaruh seperti temperatur, waktu tahan dan cooling rate (Alwarits dkk, 2014). Dari hasil penelitian basori yang membandingkan beberapa media pendingin, media pendingin air memberikan efek peningkatan kekerasan yang cukup baik tanpa terjadi retakan pada spesimen (Basori, 2018). Coolant merupakan media pengganti air yang biasa digunakan untuk pendingin pada radiator kendaraan. Untuk itu akan dilakukan penelitian untuk mengetahui apakah ada pengaruh kekerasan dan struktur mikro ketika baja karbon rendah di quenching media pendingin coolant dengan variasi holding time. Sebagai pembanding akan dilakukan juga pendinginan cepat dengan media oli.

\section{Prosedur Penelitian}

Metode penelitian yang digunakan pada penelitian ini adalah metode eksperimen. Eksperimen dalam definisinya adalah uji coba (trial) atau observasi khusus dengan tujuan untuk membuktikan dengan tepat setiap kondisi, sehingga kondisi yang meragukan dapat diperbaiki atau diatasi. Uraian prosedur penelitian dapat dipaparkan sebagai berikut:

1. Uji OES sampel baja karbon rendah.

Tabel 1. Hasil Uji OES Sampel Baja Karbon

\begin{tabular}{|c|c|c|c|c|}
\hline Unsur & $\mathbf{C}(\boldsymbol{\%})$. & Si (\%.) & Mn (\%) & Fe (\%) \\
\hline komposisi & 0,192 & 0,213 & 0,639 & Balance \\
\hline
\end{tabular}

Dari data pada hasil uji OES dapat ketahui kadar Karbon (C) pada sampel baja karbon tersebut berada pada nilai 0,192 maka baja karbon tersebut masuk dalam golongan Baja Karbon Rendah yang memiliki kadar Karbon berkisar diantara 0,025\%-0,25\%.

2. Proses pembuatan Spesimen

a. Setelah pengukuran, selanjutnya melakukan proses pemotongan

b. Setelah semua pemotongan selesai, selanjutnya meratakan permukaan dengan menggunakan mesin surface grinding. 
c. Menyiapkan spesimen untuk di lakukan heat treatment.

3. Proses Heat Treatment

a. Setelah pembuatan spesimen telah selesai kemudian tandai spesimen untuk dilakukan proses heat treatment.

b. Heat treatment dengan temperatur $1000^{\circ} \mathrm{C}$ dalam furnace dengan melakukan variasi holding time 30 menit, 60 menit, dan 90 menit setelah itu langsung didinginkan ke media quenching coolant dan dengan langkah yang sama kemudian didinginkan ke media quenching oli.

4. Proses Uji Kekerasan

a. Menyiapkan spesimen uji untuk non treatment dan heat treatment yang memiliki holding time berbeda serta menggunakan media quenching coolant dan oli akan diuji.

b. Memastikan mesin uji kekerasan siap digunakan.

c. Kemudian ikutilah penggunaan mesin uji keras vickers sesuai dengan SOP (Standar Operasional Prosedur) yang telah ada.

5. Pemolesan spesimen untuk pengamatan struktur mikro

a. Siapkan spesimen dan amplas yang akan digunakan dalam proses pemolesan.

b. Kemudian amplas spesimen menggunakan mesin poles otomatis, dimulai dengan amplas $120 \mathrm{~s} / \mathrm{d} 2000$.

c. Setelah itu, poleslah spesimen ditambah dengan autosol di atas kain halus agar mendapatkan hasil yang bersih mengkilap seperti kaca.

d. Setelah spesimen sudah terlihat seperti kaca, langkah selanjutnya pengetsaan.

6. Proses Pengetsaan

a. Setelah spesimen sudah terlihat seperti kaca, langkah selanjutnya pengetsaan.

b. Membuat larutan etsa dengn komposisi asam nitrat $\left(\mathrm{HNO}_{3}\right)$ sebanyak $4 \%$ dicampur dengan Alkohol sebanyak $96 \%$.

c. Setelah larutan etsa sudah jadi, langkah selanjutnya adalah celupkan spesimen kedalam larutan etsa pada waktu yang berbeda untuk setiap spesimen.

d. Setelah dicelupkan selama \pm 30 detik, kemudian keringkan dengan hair dryer sambil di usap menggunakan tisu.

7. Proses Pengamatan Struktur Mikro

a. Setelah spesimen sudah kering, kemudian letakkan spesimen pada mikroskop optik.

b. Setelah itu lihatlah struktur mikro yang terbentuk pada monitor atau secara komputerisasi.

\section{Hasil Penelitian}

\section{a. Hasil Uji Kekerasan}

Hasil uji kekerasan dari spesimen yang telah dilakukan proses heat treatment dengan holding time yang berbeda-beda dan dengan media pendingin yang berbeda-beda yaitu coolant dan oli.

Tabel 2. Nilai Kekerasan Vickers Spesimen Non Tratment

\begin{tabular}{|c|c|c|}
\hline Identasi & $\begin{array}{c}\text { Kekerasan } \\
\text { (VHN) }\end{array}$ & $\begin{array}{c}\text { Rata Rata } \\
\text { kekerasan (VHN) }\end{array}$ \\
\hline $\mathbf{1}$ & 182,8 & \\
\hline $\mathbf{2}$ & 186,4 & \multirow{2}{*}{184,98} \\
\hline $\mathbf{3}$ & 188,6 & \\
\hline $\mathbf{4}$ & 182,5 & \\
\hline $\mathbf{5}$ & 184,6 & \\
\hline
\end{tabular}

Dari hasil uji kekerasan dengan metode vickers didapatkan nilai 184,98 VHN untuk spesimen non treatment (lihat tabel 2). Sedangkan untuk spesimen quenching coolant dengan variasi holding time 30, 60, dan 90 menit masing-masing adalah 216,22 VHN, 264,66 VHN dan 302,84 VHN (lihat tabel 3). Terakhir pada untuk spesimen quenching oli dengan variasi holding time 30, 60, dan 90 menit masing-masing adalah 201,14 VHN, 243,2VHN dan 276,3VHN (lihat tabel 4).

Tabel 3. Nilai Kekerasan Vickers Spesimen Quenching Coolant 


\begin{tabular}{|c|c|c|c|c|}
\hline No & Spesimen & Identasi & $\begin{array}{c}\text { Kekerasan } \\
\text { (VHN) }\end{array}$ & $\begin{array}{c}\text { Rata Rata } \\
\text { kekerasan (VHN) }\end{array}$ \\
\hline & \multirow{5}{*}{30 menit } & 1 & 216,8 & \multirow{5}{*}{216,22} \\
\hline & & 2 & 212,4 & \\
\hline & & 3 & 218 & \\
\hline & & 4 & 216,5 & \\
\hline & & 5 & 217,4 & \\
\hline & \multirow{5}{*}{60 menit } & 1 & 262 & \multirow{5}{*}{264,66} \\
\hline & & 2 & 268,8 & \\
\hline & & 3 & 262,3 & \\
\hline & & 4 & 264,8 & \\
\hline & & 5 & 265,4 & \\
\hline & \multirow{5}{*}{90 menit } & 1 & 284,9 & \multirow{5}{*}{302,84} \\
\hline & & 2 & 306,2 & \\
\hline & & 3 & 285,2 & \\
\hline & & 4 & 328,9 & \\
\hline & & 5 & 309 & \\
\hline
\end{tabular}

Tabel 2. Nilai Kekerasan Vickers Spesimen Quenching Oli

\begin{tabular}{|c|c|c|c|}
\hline Holding Time & Identasi & $\begin{array}{c}\text { Kekerasan } \\
\text { (VHN) }\end{array}$ & $\begin{array}{c}\text { Rata Rata } \\
\text { kekerasan }(\text { VHN) }\end{array}$ \\
\hline \multirow{5}{*}{30 menit } & 1 & 200,7 & \multirow{5}{*}{201,14} \\
\hline & 2 & 202,6 & \\
\hline & 3 & 200,9 & \\
\hline & 4 & 201,3 & \\
\hline & 5 & 200,2 & \\
\hline \multirow{5}{*}{60 menit } & 1 & 246,6 & \multirow{5}{*}{243,2} \\
\hline & 2 & 238,9 & \\
\hline & 3 & 242,5 & \\
\hline & 4 & 245 & \\
\hline & 5 & 243 & \\
\hline \multirow{5}{*}{90 menit } & 1 & 281,4 & \multirow{5}{*}{276,3} \\
\hline & 2 & 262,6 & \\
\hline & 3 & 287,4 & \\
\hline & 4 & 283,3 & \\
\hline & 5 & 266,8 & \\
\hline
\end{tabular}

Dari tabel 2 sampai dengan tabel 4 kemudian angka rata-ratanya dibuat dalam grafik agar mudah dalam membandingkan fenomena pada tiap-tiap spesimen.

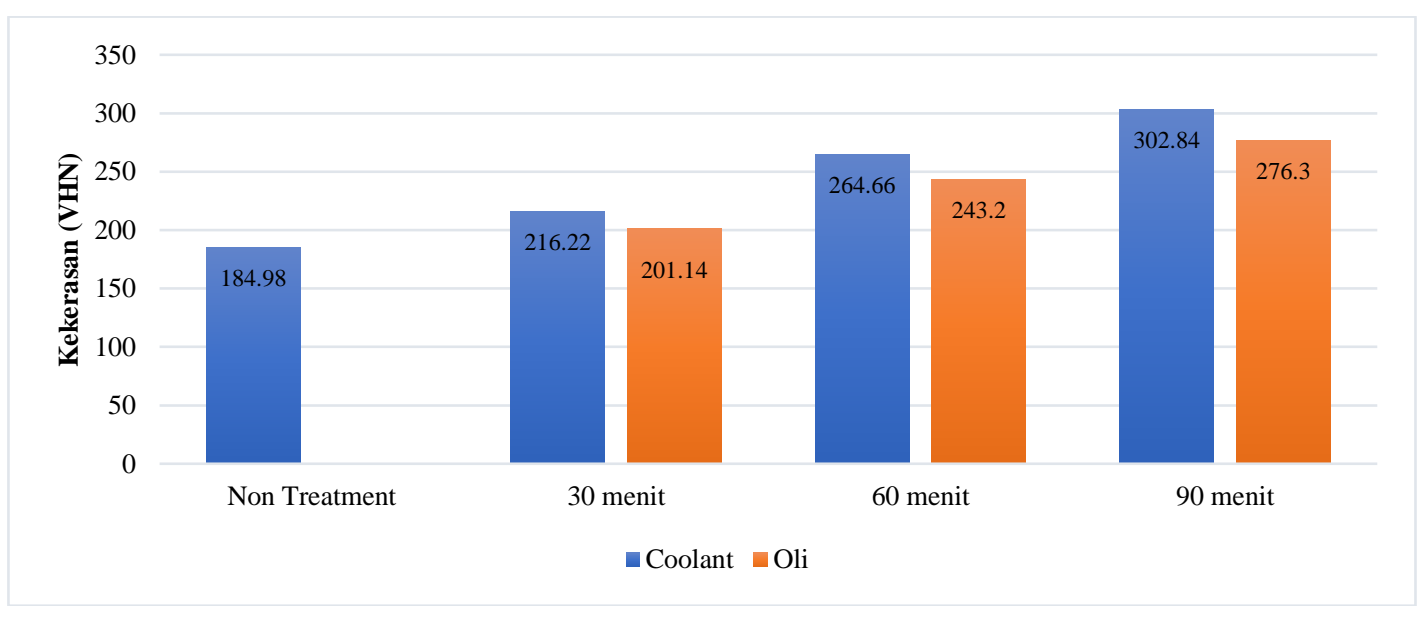

Gambar 1 Grafik Rata - Rata Nilai Kekerasan Hasil Uji Keras Vickers 
Berdasarkan gambar 1, dapat terlihat fenomena kekerasan pada tiap-tiap spesimen. Dapat terlihat bahwa semakin lama holding time maka akan semakin tinggi kekerasannya. Hal ini terjadi pada dua media pendingin yang digunakan yaitu oli dan coolant, akan tetapi media pendingin coolant menghasilkan kekerasan lebih tinggi jika dibandingkan dengan oli. Hal ini mengindikasikan bahwa cooling rate dari media coolant lebih cepat jika dibandingkan dengan media oli. Sehingga spesimen yang di quenching dengan media coolant menghasilkan kekerasan yang lebih tinggi dari oli.

\section{b. Hasil Pengamatan Struktur Mikro}

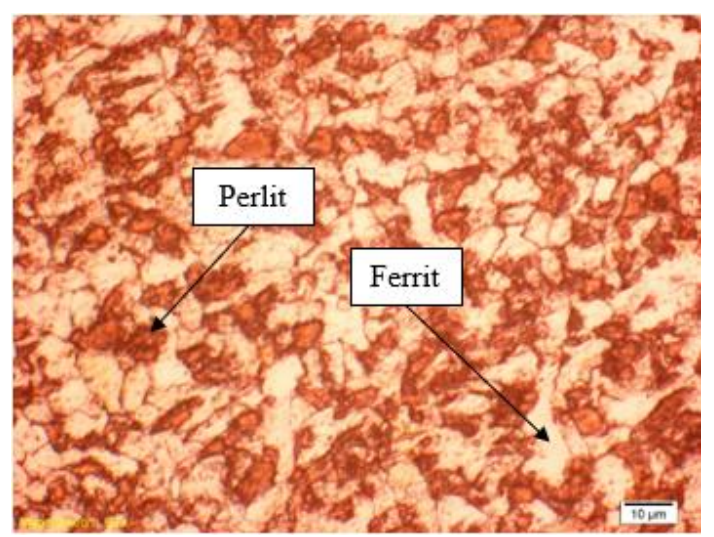

\section{Gambar 2. Struktur Mikro pada Spesimen Non Treatment}

Pada Gambar 2 di atas dapat dilihat, struktur mikro yang terdapat pada spesimen baja karbon rendah yang tidak mendapat perlakuan panas (non treatment). Pada struktur mikronya hanya terdapat fasa ferrit dan perlit saja. Dimana ferrit yang berwarna putih dengan sifat lunak dan perlit yang berwarna gelap dengan sifat kuat dan cukup keras.

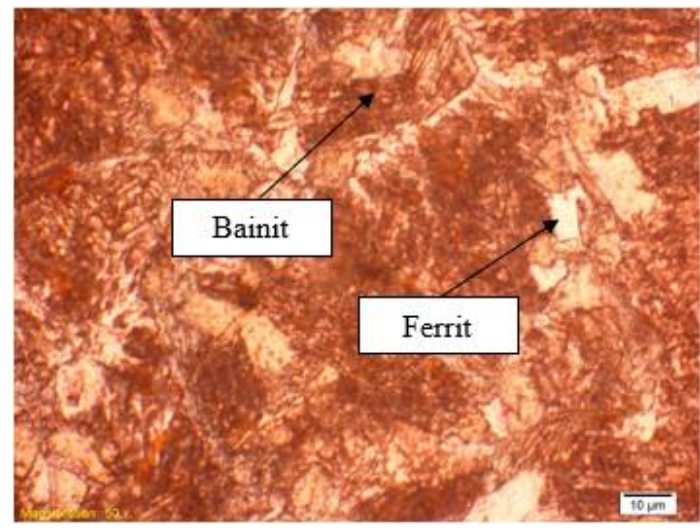

Gambar 3. Struktur mikro pada spesimen holding time 30 menit dan media pendingin coolant

Pada Gambar 3 di atas dapat dilihat, terbentuk fasa baru yang bernama fasa bainit. Fasa bainit yang terbentuk pada spesimen ini cukup dominan dibandingkan dengan fasa ferritnya. Berdasarkan pengamatan struktur mikro tersebut, menunjukkan spesimen ini lebih keras dibandingkan dengan spesimen tanpa perlakuan panas pada Gambar 2 yang hanya terdapat fasa ferrit dan perlit saja. Hal ini sesuai dengan hasil uji kekerasannya, spesimen ini memiliki nilai kekerasan yang sedikit lebih besar 31,24 VHN dibandingkan dengan spesimen tanpa perlakuan panas. 


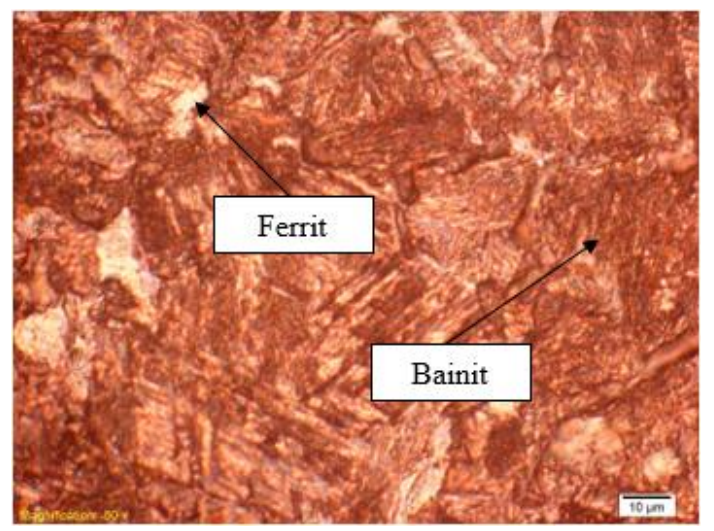

Gambar 4. Struktur mikro pada spesimen holding time 60 menit dan media pendingin coolant

Pada Gambar 4. di atas dapat dilihat, fasa bainit yang terbentuk lebih dominan daripada fasa ferrit yang terbentuk. Berdasarkan pengamatan struktur mikro tersebut, lebih banyak fasa bainit yang terbentuk menunjukkan spesimen ini lebih keras dibandingkan dengan spesimen tanpa perlakuan panas pada Gambar 2. Hal ini sesuai dengan hasil uji kekerasannya, base spesimen ini memiliki nilai kekerasan lebih besar 48,44 VHN dibandingkan dengan spesimen tanpa perlakuan panas.

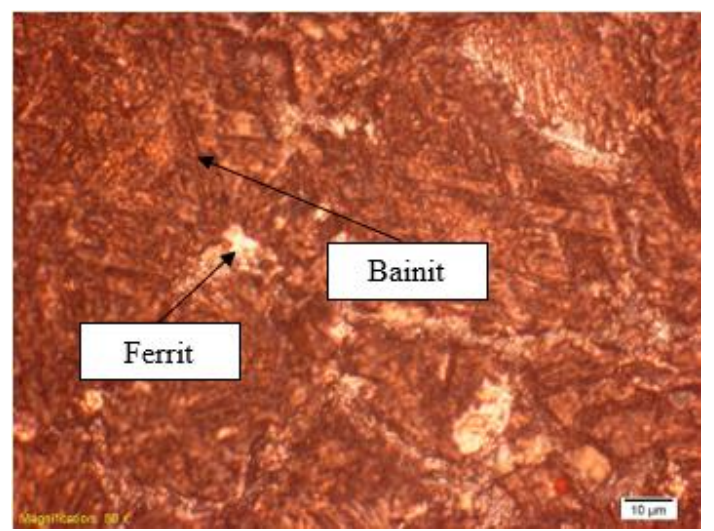

Gambar 5. Struktur mikro pada spesimen holding time 90 menit dan media pendingin coolant

Pada Gambar 5 di atas dapat dilihat, fasa bainit yang terbentuk sangat dominan dibandingkan fasa ferrit yang terbentuk. Berdasarkan pengamatan struktur mikro tersebut, semakin dominannya fasa bainit yang terbentuk menunjukkan spesimen ini lebih keras dibandingkan dengan spesimen holding time 30 menit dan media pendingin coolant pada Gambar 3 dan spesimen holding time 60 menit dan media pendingin coolant pada Gambar 4. Hal ini sesuai dengan hasil uji kekerasannya, spesimen ini memiliki nilai kekerasan yang lebih besar terhadap spesimen yang terdapat pada Gambar 3 dan Gambar 4, selain itu spesimen ini merupakan spesimen dengan nilai kekerasan tertinggi yang memiliki nilai sebesar 302,84 VHN.

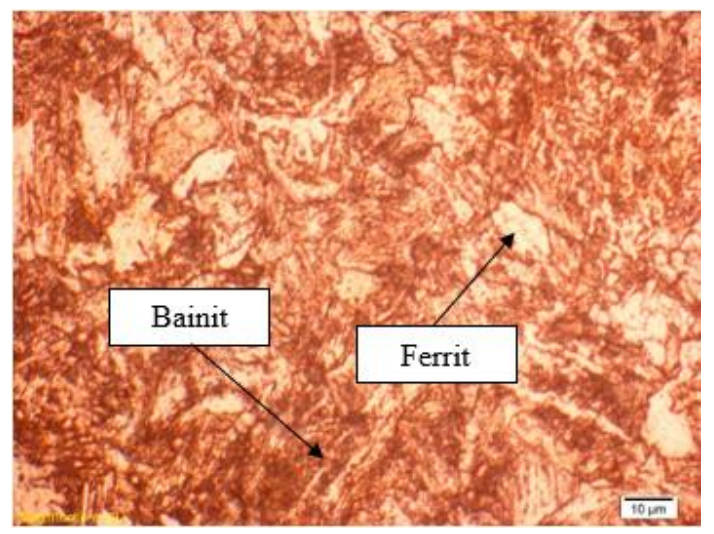

Gambar 6. Struktur mikro pada spesimen holding time 30 menit dan media pendingin oli 
Pada Gambar 6 di atas dapat dilihat untuk fasa bainit yang terbentuk tidak dominan, justru fasa ferrit yang terbentuk sangat dominan. Berdasarkan pengamatan struktur mikro tersebut, menunjukkan spesimen ini lebih lunak dibandingkan dengan spesimen pada Gambar 3, 4, dan 5, hanya lebih keras dibandingkan dengan spesimen non treatment pada Gambar 2 yang hanya terdapat fasa ferrit dan perlit saja. Hal ini sesuai dengan hasil uji kekerasannya yang nilai kekerasannya berada di di bawah semua spesimen yang dilakukan non treatment, nilai kekerasan spesimen ini hanya lebih besar 16,16 VHN terhadap spesimen non treatment.

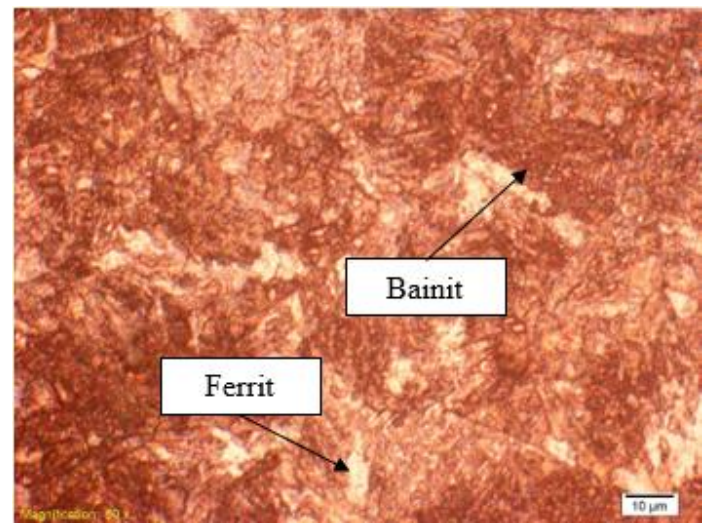

Gambar 7. Struktur mikro pada spesimen holding time 60 menit dan media pendingin oli

Pada Gambar 7 di atas dapat dilihat, fasa bainit dan fasa ferrit pada base spesimen ini sama-sama cukup dominan. Berdasarkan pengamatan struktur mikro tersebut, lebih banyaknya fasa bainit yang terbentuk menunjukkan spesimen ini lebih keras dibandingkan dengan spesimen holding time 30 menit dan media pendingin oli pada Gambar 6. Hal ini sesuai dengan hasil uji kekerasannya, spesimen ini memiliki nilai kekerasan yang lebih besar 40.66 VHN dibandingkan dengan spesimen holding time 30 menit dan media pendingin oli pada Gambar 6.

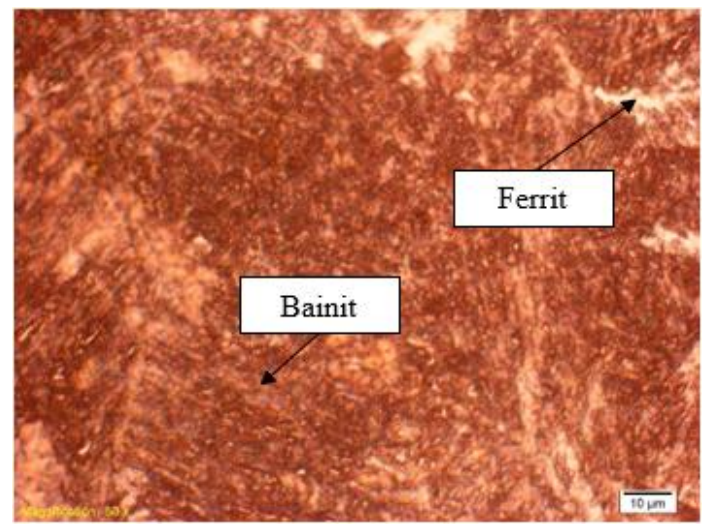

Gambar 8. Struktur mikro pada spesimen holding time 90 menit dan media pendingin oli

Pada Gambar 8 di atas dapat dilihat, fasa bainit yang terbentuk sangat dominan disamping fasa ferrrit yang terbentuk. Berdasarkan pengamatan struktur mikro tersebut, dominannya fasa bainit yang terbentuk menunjukkan base spesimen ini lebih keras dibandingkan dengan base spesimen pada Gambar 7 dan 8, namun tidak lebih keras dibandingkan dengan spesimen holding time 90 menit dan media pendingin coolant pada Gambar 5. Hal ini sesuai dengan hasil uji kekerasannya, pada spesimen ini memiliki nilai kekerasan yang lebih tinggi dibandingkan dengan spesimen pada Gambar 7 dan Gambar 8. Spesimen ini memiliki nilai kekerasan tertinggi kedua dengan selisih $26,54 \mathrm{VHN}$ terhadap spesimen holding time 90 menit dan media pendingin coolant pada Gambar 5 yang memiliki nilai kekerasan tertinggi.

\section{Kesimpulan}

1. Holding time selama 90 menit pada spesimen weld menghasilkan nilai kekerasan yang lebih tinggi

2. Spesimen yang dilakukan quenching dengan coolant memiliki nilai kekerasan 302,84 VHN, sedangkan yang dilakukan quenching dengan oli memiliki nilai kekerasan 276,3VHN. 
3. Material yang memiliki nilai kekerasan tinggi distribusi fasa yang terbentuk di dominasi fasa martensit, sedangkan yang memiliki nilai kekerasan rendah hanya di dominasi fasa ferrit dan fasa pearlit saja.

\section{Daftar Pustaka}

Alwarits, A., Daswarman, D., \& Nasir, M. (2014). Pengaruh Media Pendingin Pada Proses Hardening Terhadap Peningkatan Kekerasan Baja Karbon Sedang. Automotive Engineering Education Journals, 2(2).

Murtiono, A. (2012). Pengaruh quenching dan tempering terhadap kekerasan dan kekuatan tarik serta struktur mikro baja karbon sedang untuk mata pisau pemanen sawit. $e$-Dinamis, 2(2).

Purwanto, H. (2011). Analisa Quenching Pada Baja Karbon Rendah Dengan Media Solar. Jurnal Ilmiah Momentum, 7(1).

Setiamarga, B. H., Kurniawati, N., \& Rumendi, U. (2017). Pack carburizing pada sprocket sepeda motor dengan material baja karbon rendah. Mesin, 21(1), 28-33.

Subagiyo, S. (2017). Analisis Hasil Kekerasan Metode Vikers Dengan Variasi Gaya Pembebanan Pada Baja. Majapahit Techno: Jurnal Ilmiah dan Teknologi, 6(2), 09-14.

Basori, B. (2018). Pengaruh Media Quenching terhadap Kekerasan dan Struktur Mikro Paska Hardfacing. Jurnal Kajian Teknik Mesin, 3(2), 66-72. 